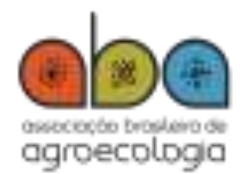

ISSN: $1980-9735$

DOI: 10.33240/rba.v16i1.23182

Vol. 16 | No 1 | p.03-15 | 2021

ARTIGO

\title{
AGRICULTURA FAMILIAR E POLÍTICAS PÚBLICAS: \\ ESTUDO DE CASO NA COMUNIDADE VILA RESSACA DA PEDREIRA, MACAPÁ, AMAPÁ, BRASIL \\ Family farming and public policies: Vila Ressaca da Pedreira, Macapá, Amapá, Brazil,
}

case study

Olivan Do Nascimento Saraiva ${ }^{1}$ e Wardsson Lustrino Borges ${ }^{2,3}$

1 Universidade Federal do Amapá.

E-mail: olivannsaraiva@gmail.com

2 Embrapa Amapá.

3 Embrapa Agroindústria Tropical.

E-mail: wardsson.borges@embrapa.br

Recebido em: 02/12/2020

Aceito para publicação em: 18/1/2021

Correspondência para: wardsson.borges@embrapa.br

\section{RESUMO}

A análise da adoção de políticas públicas para a agricultura familiar, em diferentes contextos socioeconômicos, revela resultados importantes para a compreensão do desenvolvimento rural. Objetivou-se, neste trabalho, avaliar o nível de adoção, por parte dos agricultores familiares da comunidade Vila Ressaca da Pedreira, Macapá - AP, de políticas públicas voltadas para promoção da agricultura familiar. Nós adotamos a aplicação de formulários semiestruturados, com questões relativas às principais políticas públicas implementadas no estado, para um público total de 32 famílias de agricultores. Observou-se que 87,5\%, 67,7\% e 38,7\% das famílias foram atendidas pelo serviço oficial de extensão rural e assistência técnica, programa de aquisição de alimentos e pelo programa nacional de alimentação escolar, respectivamente. Por outro lado, o programa nacional de fortalecimento da agricultura familiar, principal política pública para a agricultura familiar, foi acessado por apenas $6,25 \%$ dos entrevistados.

Palavras-chave: Agroecologia. Produção orgânica. Fruticultura. Sistema agroflorestal. Pronaf.

\section{ABSTRACT}

The analysis of the adoption of public policies for family farming in different socioeconomic contexts reveals important results for understanding rural development. The objective of this work was to evaluate the level of adoption by family farmers in the Vila Ressaca da Pedreira, Macapá - AP, of public policies aimed at promoting family farming development. We adopted the application of forms, with questions related to the main public policies implemented in the state for a total of 32 families. It was observed that $87.5 \%, 67.7 \%$ and $38.7 \%$ of the families were attended by the official rural extension service, the food acquisition program and the national school feeding program (government procurement), respectively. On the other hand, the national program for strengthening family farming, which is the main public policy for family farming in Brazil, was accessed by only $6.25 \%$ of the interviewed families,

Keywords: Agroecology. Organic production. Fruit crop. Agroforestry system. Pronaf. 
Introdução

As políticas públicas e as diretrizes das ações do poder público podem ser entendidas como princípios norteadores, conjunto de regras e de procedimentos para as relações entre poder público e a sociedade. São fundamentadas no âmbito legal, por meio de instrumentos, como leis, decretos e regulamentos, em atendimento a determinado anseio social, e definem a capacidade dos governos de implementar mecanismos que minimizem as necessidades sociais na perspectiva do desenvolvimento sustentável (CAPORAL e PETERSEN, 2011).

As primeiras iniciativas voltadas ao desenvolvimento rural brasileiro não são recentes. Todavia, nas últimas décadas, têm se intensificado a implementação de políticas públicas voltadas para a promoção do desenvolvimento rural brasileiro (FINATTO e SALAMONI, 2008). Na Amazônia, inúmeras iniciativas governamentais foram criadas, visando promover o povoamento da região, além de buscar o desenvolvimento de aptidões econômicas, a partir da exploração agrícola, pecuária e mineral, no interior dos estados que compõem a região Norte. A criação da Superintendência de Desenvolvimento da Amazônia-SUDAM, do Programa de Integração Nacional-PIN, e agentes financeiros, como o Banco da Amazônia e abertura de rodovias para a interligação entre cidades e o escoamento da produção, dentre as quais a Rodovia BR 316, BR 230, BR 163 e perimetral Norte (LÉNA, 1988; KOHLHEPP, 2002 e BECKER, 2010), foram ações desenvolvidas, com o sentido de promover o desenvolvimento da região.

Em relação à promoção da agricultura familiar, pode-se afirmar que ela tem se tornado cada vez mais possível e eficaz, graças à institucionalização do Programa Nacional de Fortalecimento da Agricultura Familiar (PRONAF), principal política pública brasileira para esse grupo social historicamente desassistido pelo Estado Brasileiro. Conforme os parâmetros legais, considera-se como agricultor familiar o indivíduo que: I - não detenha, a qualquer título, área maior do que 4 (quatro) módulos fiscais; II - utilize, predominantemente, mão de obra da própria família nas atividades econômicas do seu estabelecimento ou empreendimento; III - tenha renda familiar predominantemente originada de atividades econômicas, vinculadas ao próprio estabelecimento ou empreendimento e IV - dirija seu estabelecimento ou empreendimento com sua família (BRASIL, 2006).

Segundo dados do IBGE (2017), entre os 8.507 estabelecimentos agrícolas existentes no Estado do Amapá, 82,09\% são conduzidos por agricultores familiares, e a soma das áreas utilizadas por esses agricultores representa $13,04 \%$ da área total ocupada pelos estabelecimentos agropecuários no Estado. Assim, mesmo possuindo áreas pequenas, esses agricultores assumem um papel de extrema relevância para a diminuição das desigualdades sociais, diversidade da produção, segurança alimentar e a melhoria da qualidade de vida no campo.

No processo de construção e implementação das políticas públicas, as instituições governamentais assumem um papel de suma importância, por garantir que as diretrizes do poder público, constituído como ente organizacional, sejam levadas a cabo. Não obstante, dada a precariedade histórica das políticas públicas voltadas para o meio rural, a participação dos agricultores e seus mecanismos de representação também é de significativa importância, por constituir uma espécie de correlação de forças para a inserção dos interesses dos diferentes tipos de agricultores familiares. A participação das instituições e organizações da sociedade civil é capaz de determinar os rumos das políticas públicas e a interação entre entes governamentais das diversas esferas, e a sociedade tem gerado um efeito positivo no que diz respeito ao suprimento das demandas.

A agricultura familiar no Amapá é caracterizada pela produção de subsistência, com comercialização de uma pequena parte excedente da produção (LOMBA e SILVA, 2014), tornando-se necessário o emprego de mecanismos e políticas públicas diversificadas, capazes de promover resultados efetivos para promoção do desenvolvimento em todas as dimensões. Diversos estudos conduzidos no Brasil apontam para a melhoria na qualidade de vida dos agricultores familiares 
beneficiados por políticas públicas, considerando a geração de emprego e renda, movimentação econômica, acesso a mercados, segurança alimentar e valorização dos aspectos culturais nas comunidades rurais (AZEVEDO e PESSOA, 2011; FREITAS et al., 2012). A necessidade de adaptações relacionadas à destinação de recursos, observância de aspectos regionais e na própria operacionalização de algumas políticas públicas, tem sido apontada com objetivo de aumentar a efetividade e satisfação dos beneficiários (SARON e HESPANHOL, 2012; SIMÃO et al., 2014; MEDINA e NOVAES, 2014; BALDISERA et al., 2019).

Nesse sentido, o presente estudo objetivou analisar a adoção de políticas públicas voltadas para a promoção do desenvolvimento rural, em uma comunidade composta por agricultores familiares, no município de Macapá, estado do Amapá.

\section{Metodologia}

O Estado do Amapá está dividido em 16 municípios, sendo que, aproximadamente, $60 \%$ da população do Estado reside na capital Macapá. Para a presente pesquisa, optou-se por delimitar como período de adoção das políticas públicas, o intervalo entre os anos de 2006 e 2018, e a experiência de 32 famílias de agricultores familiares, moradores da comunidade rural Vila Ressaca da Pedreira, localizada na zona rural de Macapá. Esse recorte foi delimitado em função de, nos últimos anos, ter ocorrido uma intensificação de políticas voltadas para a agricultura familiar, no âmbito nacional, e pelas peculiaridades da comunidade, como distância em relação ao mercado, histórico de ocupação e condições ambientais, sociais e econômicas atuais.

A comunidade rural Vila Ressaca da Pedreira possui, aproximadamente, 150 anos de

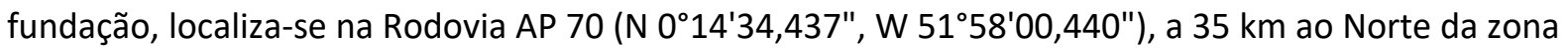
urbana de Macapá (Figura 1). A comunidade, ao longo dos anos, tem sido contemplada com políticas públicas, como políticas habitacionais (Figura 2), que colaboraram para mudanças no cotidiano das famílias e promovem melhorias na qualidade de vida. A população é constituída, principalmente, por agricultores familiares e descendentes quilombolas. Atualmente, a comunidade possui, aproximadamente, 250 famílias, das quais $42 \%$ (105 famílias) têm a agricultura como a principal atividade, e se dedicam, em sua maioria, à produção de frutas, hortaliças e criação de animais.

Ao longo da última década, a paisagem que circunda a comunidade tem sido modificada pela expansão do plantio mecanizado das culturas da soja e do milho, formando mosaicos na paisagem. Por um lado, uma cultura de grão, capitalizada e tecnificada, por outro, agricultores familiares tradicionais, com baixo nível de acesso a tecnologias.

O estudo foi baseado na aplicação de um questionário semiestruturado, por meio de entrevista, para a compreensão da adoção das políticas públicas conforme, proposto por Gil (2009); Yin (2010); Froblich e Froblich (2014). Inicialmente, realizou-se um pré-teste, para a adaptação do tempo, linguagem e entendimento das perguntas da entrevista. Para isso, duas lideranças, agricultores conhecedores da realidade e que exercem papel de representantes dos agricultores, foram identificadas, e o formulário foi validado. Após a validação, foi realizada a aplicação do formulário a 30\% (32) das famílias de agricultores familiares, que exercem atividades agropecuárias na comunidade, selecionados aleatoriamente.

O estudo foi previamente cadastrado na Plataforma Brasil (Parecer CEP 4.100.110), e todos os agricultores se declararem aptos para participar do estudo, assinando o Termo de Consentimento Livre Esclarecido (TCLE), conforme estabelece a Portaria Ministerial 466, de 12 de dezembro de 2012 (BRASIL, 2012).

As perguntas contidas no formulário abordavam questões relacionadas à adoção das políticas públicas, e foram feitas de forma oral e individual, destinadas ao responsável pelo grupo familiar, sem distinção de sexo, porém, com idade superior a 18 anos. Para isso, tornou-se necessário o uso de 
técnicas de anotação simultânea da comunicação, com uso de caderno de campo, gravação de voz dos participantes, com a utilização de gravador portátil, registros fotográficos, caminhamentos nas propriedades, além da plotagem de pontos de localização, com uso aparelho de Global Positioning System GPS (GarmimEtrex10).

As entrevistas foram realizadas no período de 15 de outubro a 24 de dezembro de 2018. Os dados coletados foram, posteriormente, sistematizados em planilhas eletrônicas. Parte das falas dos agricultores foram transcritas e sistematizadas em planilha, com vistas a complementação das análises.

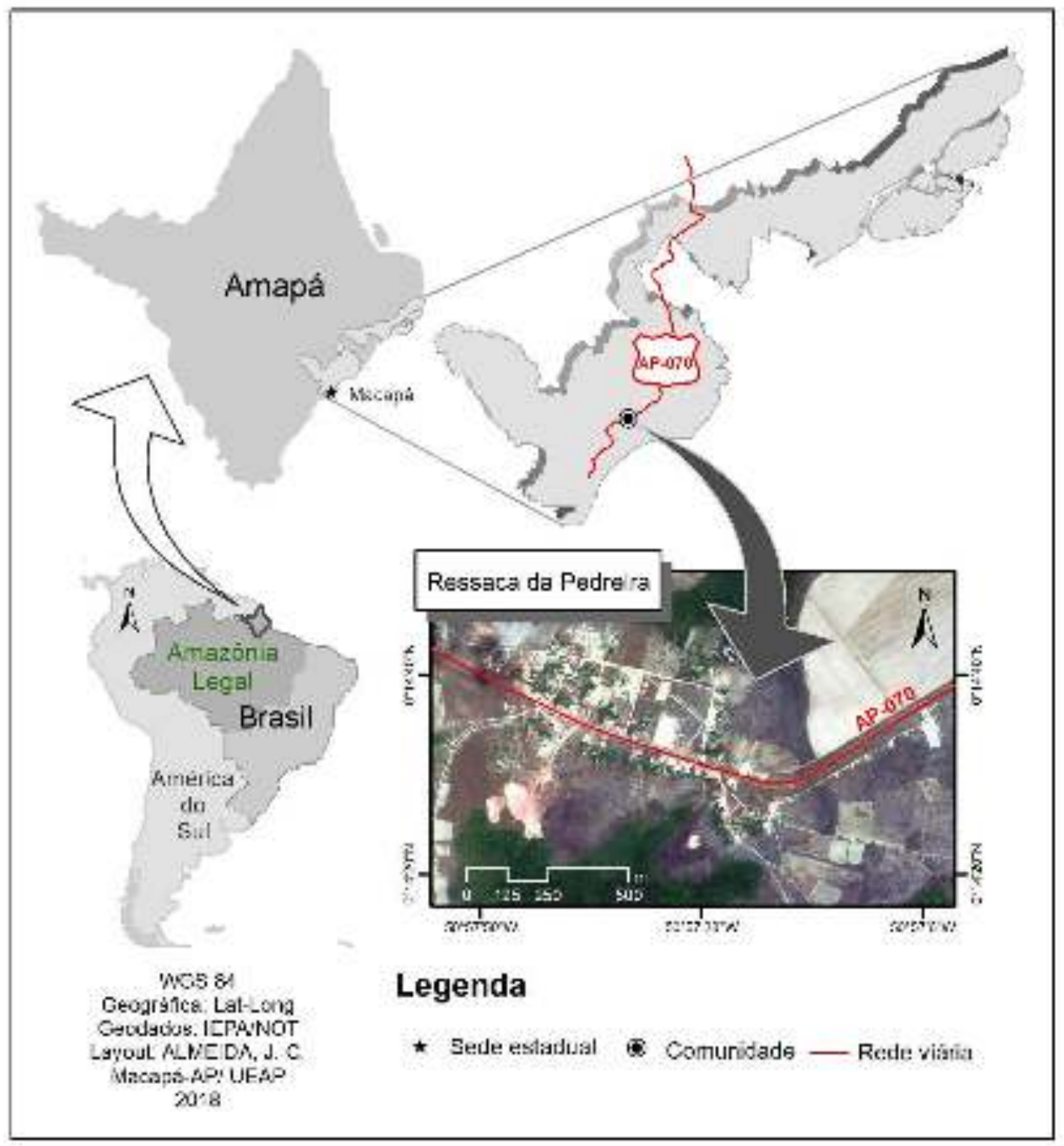

Figura 1. Localização da Comunidade Vila Ressaca da Pedreira, Macapá, Amapá. 

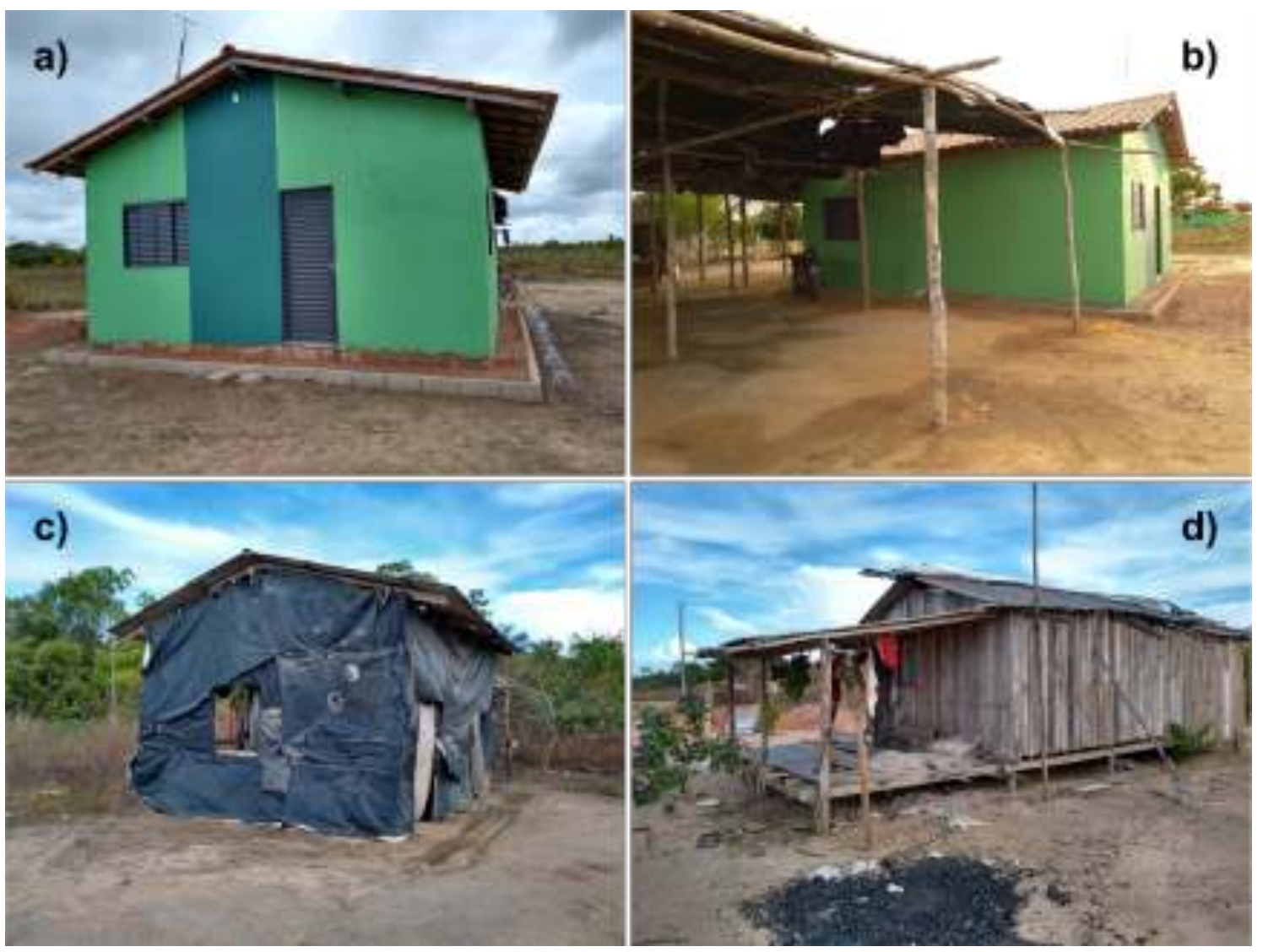

Figura 2. Padrão de residência das famílias na comunidade Vila Ressaca da Pedreira, Macapá, AP, contempladas (A e B) ou não (C e D) por política pública habitacional, Minha Casa Minha Vida Quilombola. 2018.

\section{Resultados e Discussão}

As entrevistas evidenciaram a adoção/execução de seis principais políticas públicas voltadas para agricultores familiares, na comunidade Vila Ressaca da Pedreira, sendo elas: Assistência Técnica e Extensão Rural (ATER), Programa de Produção Integrada (PPI), Programa de Aquisição de Alimento (PAA), Programa Nacional de Alimentação Escolar (PNAE), Programa Territorial da Agricultura Familiar e Floresta (PROTAF) e Programa Nacional de Fortalecimento da Agricultura Familiar (PRONAF) (Figura 3). 


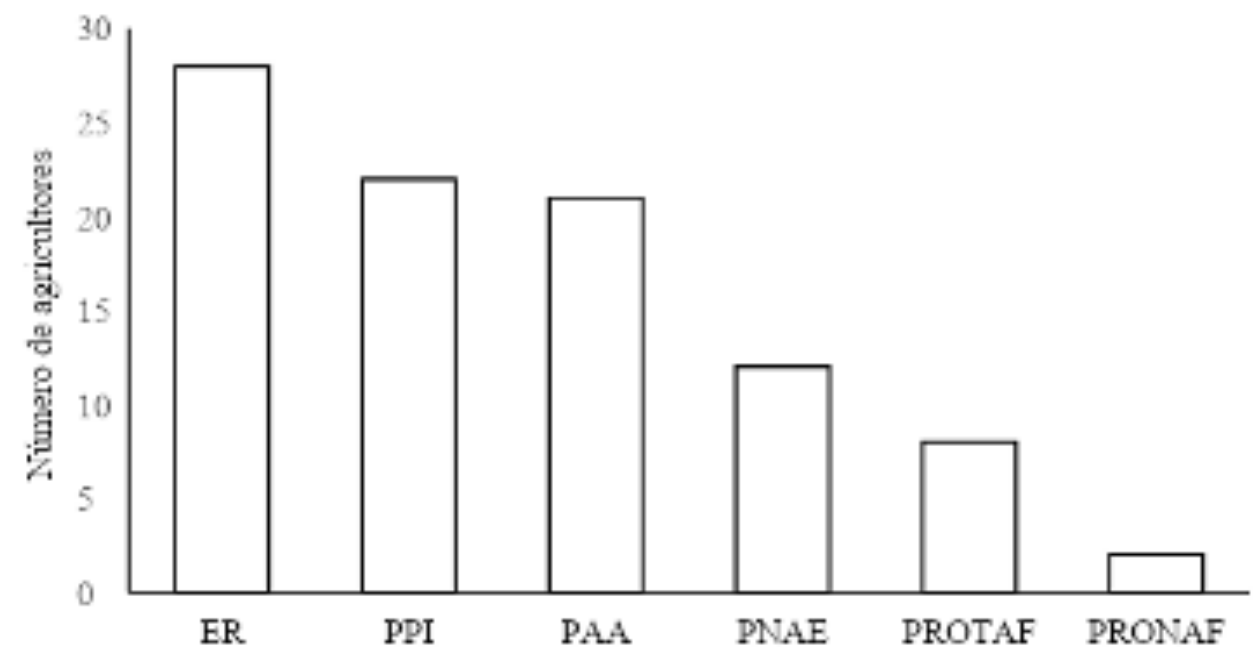

Figura 3. Número de agricultores que acessaram as políticas públicas Extensão Rural (ER), Programa de Produção Integrada (PPI), Programa de Aquisição de Alimentos (PAA), Programa Nacional de Alimentação Escolar (PNAE), Programa Territorial da Agricultura Familiar e Floresta (PROTAF) e Programa Nacional de Fortalecimento da Agricultura Familiar (PRONAF), no período de 2006 a 2018, na comunidade Vila Ressaca Pedreira, Macapá, Amapá, Brasil.

A Extensão Rural assume um papel fundamental para o desenvolvimento rural da comunidade. $87,5 \%$ dos agricultores familiares afirmaram que as atividades foram acompanhadas por algum técnico do serviço de extensão rural oficial, pelo menos uma ocasião por ano. As atividades desenvolvidas pela assistência técnica estão relacionadas às orientações para uso de insumos, controle de praga e distribuição de sementes. Elas têm sido coordenadas pelo Instituto de Desenvolvimento Rural do Amapá (RURAP).

De acordo com Assis (2006), embora inserida em lógicas produtivas locais, a agricultura familiar se expõe a um paradigma competitivo de ordem global. No entanto, independente dos mercados aos quais destinam sua produção ou canais de comercialização, devem contar com ferramentas que apoiam as decisões. Nesse sentido, a assistência técnica para os agricultores não é considerada apenas útil, mas indispensável para o desenvolvimento.

A frequência dos atendimentos varia de mensal, trimestral, semestral e anual. A partir de 2015, observou-se um aumento na frequência de visitas aos produtores e, provavelmente, isso ocorreu graças à implementação da política estadual do PPI e à integração de esforços entre diferentes instituições (Embrapa), e Instituto de Desenvolvimento Rural do Amapá (RURAP) conforme preconiza a Política Nacional de Assistência Técnica e Extensão Rural (PNATER) (DIAS, 2007).

A baixa interação institucional é um dos principais gargalos para melhorar o desempenho da assistência técnica (LANDINI, 2015), dado que a interação institucional proporciona maior eficiência quanto ao alcance dos objetivos dos programas de ATER, como a criação de alternativas apropriadas, pautadas na formação continuada de produtores beneficiários e técnicos (OLIVEIRA et al., 2013).

No presente estudo, considerando as seis políticas mencionadas e os 32 agricultores entrevistados, $97 \%$ dos agricultores acessaram, ao menos, uma política pública, nenhuma família acessou todas as seis políticas públicas encontradas e $34 \%$ das famílias acessaram três políticas públicas (Figura 4). Esse dado evidencia um baixo nível de integração entre as políticas, potencial indicador da baixa interação entre as instituições executoras e, possivelmente, é a causa da dispersão de efeitos das políticas e baixo reflexo delas sobre a qualidade de vida dos agricultores da comunidade. 


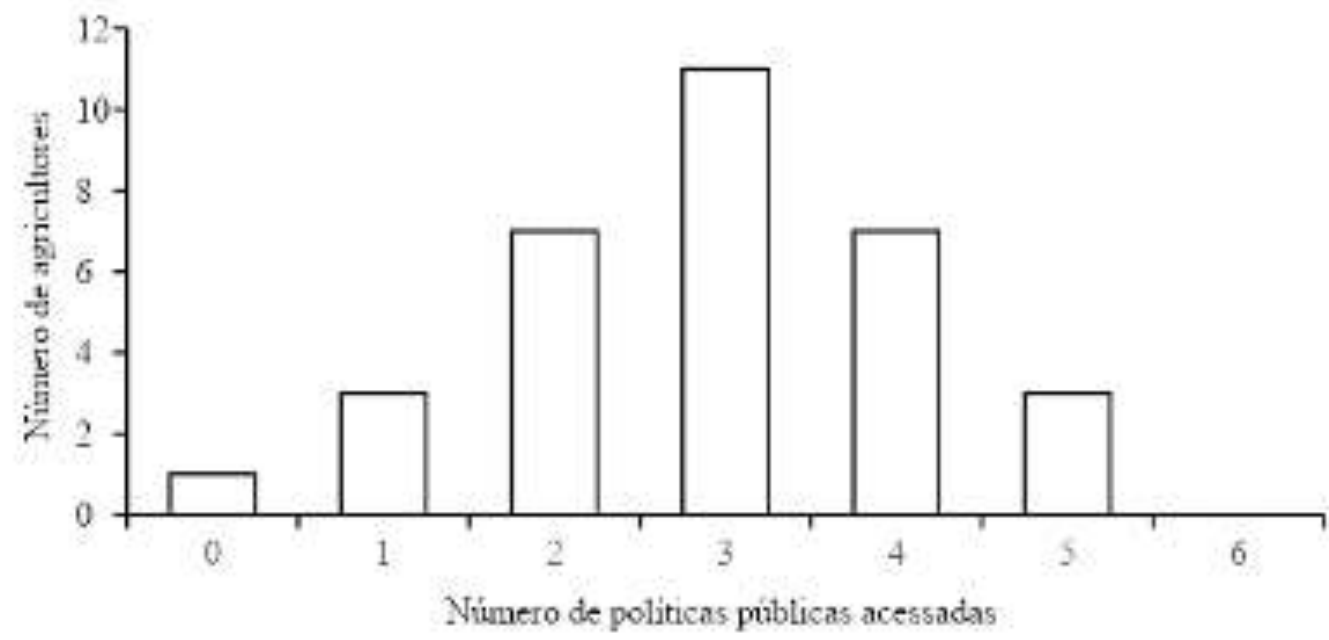

Figura 4. Relação entre o número de agricultores e o número de políticas públicas acessadas, no período de 2006 a 2018, considerando as políticas públicas de Extensão Rural (ER), Programa de Produção Integrada (PPI), Programa de Aquisição de Alimentos (PAA), Programa Nacional de Alimentação Escolar (PNAE), Programa Territorial da Agricultura Familiar e Floresta (PROTAF) e Programa Nacional de Fortalecimento da Agricultura Familiar (PRONAF), na Vila Ressaca Pedreira, Macapá, AP, Brasil

Com base no nosso levantamento, observou-se que $70,9 \%$ dos agricultores acessaram o PPI no período analisado, sendo que os primeiros acessos ocorreram em 2015, sete anos após a sua implementação no estado. Esse programa foi idealizado e implantado pela Secretaria de Desenvolvimento Rural (SDR), no ano de 2008. As atividades previstas no programa incluem preparo de áreas para os cultivos, correção de solos, adubação, fornecimento de diversos insumos e capacitação das famílias contempladas.

Na concepção do programa, duas etapas são previstas: a primeira, consiste no consorciamento de espécies de ciclo curto, como mandioca, milho, arroz e feijão, adotando o Sistema Bragantino (HURTIENNE, 2008) e, na segunda fase, os agricultores são orientados a introduzir espécies perenes, na perspectiva de se formar uma "floresta de alimentos" (Sistema Agroflorestal SAFs), em uma área de 1 ha. O consorciamento entre espécies visava, simultaneamente, a recuperação de áreas degradadas e elevação da fertilidade dos solos já antropizados (SÁ et al., 2007). O diferencial desse programa é que há um aporte financeiro, quase que integral, por parte do governo do estado, através da SDR, para a implementação dos cultivos, o que se denomina genericamente entre os produtores e técnicos de "fomento".

Para Silva e Filocreão (2014), o PPI foi criado para o fortalecimento de um modelo de agricultura sustentável, levando em consideração os aspectos sociais, econômicos e ambientais predominantes,visando superar a baixa produção de alimentos. Em tese, os investimentos do Estado se encerrariam com a implantação das culturas perenes. No entanto, na prática, esse objetivo não tem se concretizado, em função de diversos problemas na sua implementação e condução (atraso na entrega de insumos, quantidade insuficiente, etc.).

Apesar de o programa enfatizar o consorciamento, observou-se, na maioria das unidades, predominância da cultura da mandioca, e que a formação da "floresta de alimento" não tem ocorrido. No entanto, todos os agricultores que acessaram o PPI relataram a importância do programa e que ele possibilitou a comercialização dos produtos para feiras, atravessadores e transeuntes na comunidade, além da alimentação da família.

O PROTAF foi criado, em 2011, e executado até o ano de 2014. Nesse período houve 3, 2, 1 e 2 acessos por ano, totalizando oito acessos entre os 32 agricultores entrevistados na comunidade Vila Ressaca da Pedreira. O PROTAF é um programa muito parecido com o PPI, apresentando como diferenças principais a valorização de uma maior diversificação de culturas na primeira fase, mas, também, tendo como base o Sistema Bragantino, que prioriza a rotação e consórcio entre culturas, principalmente arroz, mandioca e feijão-caupi, mantendo os restos culturais na área, para melhoria da fertilidade do solo, além da valorização do componente florestal, seja plantado ou nativo (SILVA, 2018).

As primeiras experiências tiveram como objetivo principal, segundo os agricultores e representantes da comunidade, promover a diversidade cultural de espécies de ciclo curto, com adoção 
de técnicas sustentáveis, baseadas em princípios agroecológicos, como a ausência do uso de fogo, uso de cobertura morta e adubação orgânica, a partir do aproveitamento de esterco de bubalinos e aves. Para Fontes et al. (2013), essas iniciativas fortalecem o emprego de modelos de transição para uma agricultura de base ecológica, adequando o sistema produtivo à realildade dos agricultores. Nesse período, a mandioca foi a principal cultura em termos de área plantada, mas frutíferas como maracujá, graviola, melancia, banana e açaí,horticultura, meliponicultura e apicultura, também foram apoiadas (Figura 5).

O que se percebe é a utilização cada vez mais intensa dos saberes tradicionais em todos os estabelecimentos agrícolas estudados, mesmo havendo interação entre os agricultores e o poder público, aqui representado pelas instituições. Os agricultores familiares priorizam o uso de defensivos agrícolas de base natural, adubos orgânicos (estercos de bubalinos, aves), restos culturais e controle natural de insetos nas parcelas cultivadas. Tais iniciativas segundo, Valente et al. (2017), mesmo importante, ainda carecem de apoio técnico para a continuidade das práticas agroecológicas, em detrimento ao uso de agroquímicos, ainda comum entre os agricultores na comunidade.

Do ponto de vista local, essa transição agroecológica que, paulatinamente vem ocorrendo na comunidade ao longo dos anos, possui potencial para promover o desenvolvimento mais justo e igualitário, a partir da elevação de indicadores sociais, como demonstram outras experiências apontadas (OLIVEIRA et al., 2013; NODARI e GUERRA, 2015).

Com relação ao PPI e ao PROTAF, o que se percebe é que, com as mudanças no governo estadual (Executivo), os programas foram interrompidos ou retomados de acordo com a priorização do governo. Assim, o PPI foi operado entre 2008 e 2010 e, posteriormente, entre 2015 e 2018. O PROTAF operado entre 2011 e 2014. Vale ressaltar que, em ambos, a apresentação da Declaração de Aptidão ao PRONAF (DAP) e a adesão ao Sistema Bragantino são pré-requisitos para que o agricultor seja contemplado.

Políticas públicas de âmbito nacional, como o PAA e o PNAE, são relevantes, por garantirem acesso a mercados para os agricultores familiares. Para Hespanhol (2013), essas políticas apresentam duas finalidades principais: promover o acesso à alimentação e incentivar a agricultura familiar. Para cumprir esses objetivos, esses programas adquirem produtos oriundos da agricultura familiar, e os destinam a pessoas em situação de insegurança alimentar e nutricional, atendidas por instituições de redes públicas e/ou filantrópicas ou para a merenda escolar. 

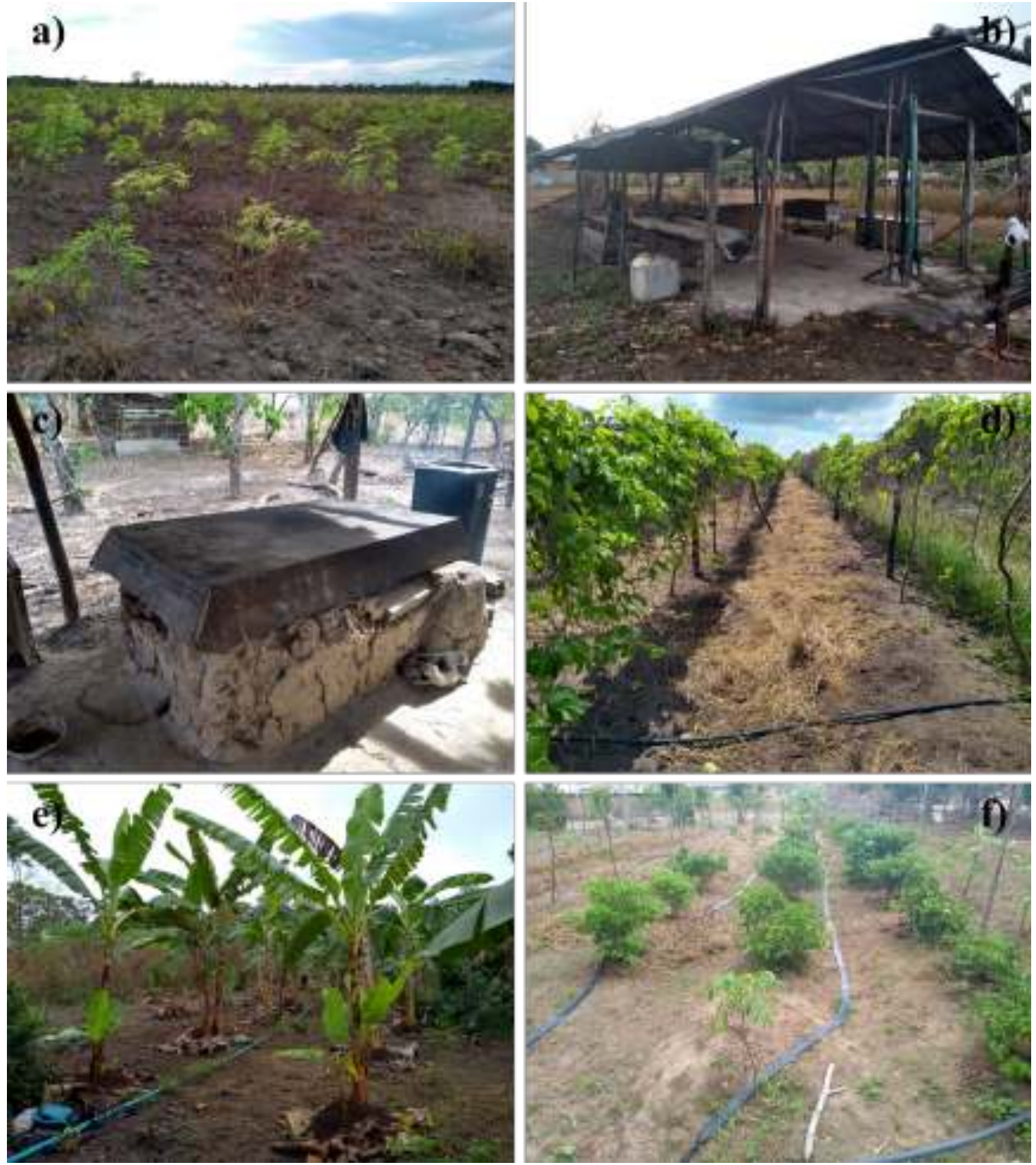

Figura 5. Representação dos cultivos de mandioca (a), maracujá (d), banana (e) e de hortaliças (f) e das instalações para processamento da mandioca e produção de farinha (b e c), frequentes na comunidade Vila Ressaca da Pereira, Macapá, Amapá. 2018.

Em 2010, um ano após ao início da execução do PAA no Estado do Amapá, 9,3\% das famílias entrevistadas foram contempladas. Nos anos de 2011 e 2012 não houve acessos entre os entrevistados e, no período analisado nesse estudo, um total de 21 agricultores acessaram o programa. A comercialização ocorreu tanto de forma coletiva para a Companhia Nacional de Abastecimento (CONAB), quanto de forma individual, por meio do Instituto de Desenvolvimento Rural do Amapá (RURAP) e Secretaria de Estado da Inclusão e Mobilização Social (SIMS).

Em relação ao PNAE, os primeiros acessos por agricultores da Vila Ressaca da Pedreira ocorreram quatro anos após a implementação do programa nacionalmente, e 38,7\% dos agricultores foram contemplados no período estudado.

A promoção de mercados institucionais como forma de superação da dificuldade de acesso a mercados por agricultores familiares é uma ferramenta indispensável na promoção do desenvolvimento rural local, pois tem promovido geração de emprego, renda e movimentação econômica dos assistidos (ELIAS et al., 2019), e o PAA e o PNAE têm sido considerados ferramentas relevantes para a promoção do 
desenvolvimento rural e da melhoria da qualidade de vida das populações rurais (CAMARGO et al., 2013; CAZELLA et al., 2016).

Libermann e Bertolini (2015) enfatizam que o PNAE é um dos programas mais abrangentes e duradouros do mundo, enquanto política de acesso a mercados. A execução do PNAE, no município de Alegre (ES), evidencia a importância da adoção de ferramentas de gestão compartilhada entre os diversos atores (RODRIGUES et al., 2017), para aumentar os ganhos por meio da formação de redes de comercialização dos produtos. No presente estudo, não se identificou qualquer mecanismo que indicasse essa tendência. Curiosamente, o PRONAF, política pública considerada como sendo a principal política pública criada nos últimos 30 anos, e grande responsável pela melhoria na qualidade de vida da população rural brasileira (GRISA e SCHNEIDER, 2014; NIEDERLE et al., 2019), foi pouco acessada pelos agricultores na Vila Ressaca da Pedreira. Apenas 6,25\% das famílias recorreram a essa ferramenta de crédito.

O baixo acesso dessa política pública reforça o que discutem Capellesso et al. (2018), o PRONAF, apesar de ser o principal catalisador de transformações no campo brasileiro, ainda está longe de suprir todas as demandas, e necessita de estímulos mais atrativos e menos centralizados, em prol de um desenvolvimento mais equitativo. Além disso, não se constatou quaisquer outras modalidades de política pública relacionada a crédito entre os agricultores que responderam a essa pesquisa de campo. $O$ que ocorre na comunidade Vila Ressaca da Pedreira, em relação ao PRONAF, não se difere do contexto nacional. Segundo Aquino et al. (2018), mais da metade dos estabelecimentos classificados como grupo "B", mesma classificação dos agricultores da comunidade, figuram-se com alto grau de vulnerabilidade socioeconômica, baixa produção e são dependentes da ajuda governamental para a permanência no campo.

A desconfiança e o receio dos agricultores familiares em contrair dívidas foram apontados como os principais responsáveis pelos baixos índices de acessos ao Pronaf, em estudo realizado com agricultores familiares no chamado "circuito das frutas", no Estado de São Paulo (ESQUERDO e BERGAMASCO, 2014).

A falta de informação sobre o programa, exigência documental considerada como grande burocracia e precaução em relação à contração de dívidas, foram os principais motivos da falta de interesse por parte dos agricultores por essa política pública, no presente estudo. Aponta um dos entrevistados.

“É muita burocracia, não ficamos conhecendo como acessar, precisamos estar sempre informados, senão não posso acessar, não gosto de dever para ninguém, imagina para o banco. Temos que ter cursos na comunidade, que treine o agricultor sobre os trâmites desses programas e o que seria necessário para ter acesso de forma antecipada."

Para Pereira e Nascimento (2014), são muitos os desafios dos agricultores em relação ao PRONAF. Para esses autores, torna-se imprescindível o planejamento e o conhecimento sobre as atividades a investir, além da aproximação com agentes bancários, a fim de conhecer sobre juros e formas de pagamentos dos créditos nas mais diversas linhas.

Schneider et al. (2004) afirmam que os juros de créditos praticados pelo PRONAF são abaixo da inflação observada no Brasil, o que, de fato, acaba por facilitar o interesse pelos recursos disponibilizados para o desenvolvimento das atividades agropecuárias. Ainda segundo esses autores, a aquisição de equipamentos, construção e manutenção de instalações, além da melhoria das atividades com recursos de custeio, são os principais motivos pelas buscas das linhas de créditos do PRONAF.

Nos municípios cearenses de Baturité, Igutau e Quixadá, a adoção do PRONAF tem promovido maiores índices de emprego e renda no campo (DAMASCENO et al., 2011). O baixo interesse nas linhas de créditos ou a redução quanto ao número de contemplados pelo PRONAF no meio rural, via de regra, significa baixo desenvolvimento, dado que os agricultores familiares possuem baixo nível de poupança para financiar a própria produção (ZANI e COSTA, 2014). A geração de outros mecanismos capazes de atrair os agricultores do estado do Amapá para o PRONAF é necessária.

\section{Considerações Finais}

Mecanismos que promovam inovação social e produtiva são necessários para promoção do desenvolvimento da comunidade Vila Ressaca da Pedreira (Macapá, Amapá, Brasil). Os dados apontam que as políticas públicas com característica de obtenção de apoio financeiro ou logística não onerosas, como 
o Programa de Assistência Técnica e Extensão Rural, o Produção Integrada e o Programa Territorial da Agricultura Familiar e Floresta, tem sido as mais acessadas na comunidade estudada. $O$ baixo nível de adoção do Programa Nacional de Fortalecimento da Agricultura Familiar (PRONAF), que é voltado para o crédito, certamente tem representado impactos negativos ao desenvolvimento da comunidade no longo prazo. O baixo nível de poupança da comunidade e a baixa efetividade das políticas públicas implementadas estão se retroalimentando e têm corroborado para a manutenção de baixos níveis de produtividade e, consequentemente, níveis reduzidos de qualidade de vida.

\section{Agradecimentos}

Os autores agradecem à Empresa Brasileira de Pesquisa Agropecuária (EMBRAPA) e à Universidade Federal do Amapá (UNIFAP) pelo suporte para realização do trabalho.

Referências Bibliográficas

AQUINO, J. R.; GAZOLLA, M.; SCHNEIDER, S. Dualismo no campo e desigualdades internas na agricultura familiar brasileira. Revista de Economia e Sociologia Rural, v. 56, n. 1, p. 123-142, 2018.

ASSIS, R.L. Desenvolvimento rural sustentável no Brasil: perspectivas a partir da integração de ações públicas e privadas com base na agroecologia. Economia Aplicada, v. 10, n. 1, p. 75-89, 2006.

AZEVEDO, F.F; PESSÔA, V.L.S. O Programa Nacional de Fortalecimento da Agricultura Familiar no Brasil: uma análise sobre a distribuição regional e setorial dos recursos. Sociedade e Natureza, $v$. 23, n. 3, p. 483-496, 2011.

BALDISERA, R.S.; DALLACORT, R.; SEABRA JUNIOR, S.; M. A. C. CARVALHO, M.A.C.; YAMASHITA, O.M. Perfil socioeconômico dos produtores (PNAE e PAA) em castanheira-MT, Sudoeste da Amazônia Legal. CAMPO-TERRITÓRIO: Revista de geografia agrária, v. 13, n. 29 Abr., 2019.

BECKER, B.K. Revisão das políticas de ocupação da Amazônia: é possível identificar modelos para projetar cenários? Revista Parcerias estratégicas, v. 06, n. 12, p. 135-159. 2010.

BRASIL. MINISTÉRIO DA SAÚDE. Resolução no 466, de 12 de dezembro de 2012. Estabelece as

Diretrizes para Pesquisa em Seres Humanos. Brasília, DF. Disponível em: https://bvsms.saude.gov.br/bvs/saudelegis/cns/2013/res0466_12_12_2012.html. Acesso: 22 de mar. 2021

BRASIL. MINISTÉRIO DO DESENVOLVIMENTO AGRÁRIO. Lei n¹1.326 de 24 de julho de 2006. Estabelece as Diretrizes para a Formulação de Política Nacional e empreendimentos Familiares Rurais. Brasília, DF. Disponível em: http://www.planalto.gov.br/ccivil_03/_ato20042006/2006/lei/l11326.htm. Acesso: 22 de mar. 2021

CAMARGO, R.A. L.; BACCARIN, J.G.; SILVA, D.B.P. O papel do Programa de Aquisição de Alimentos (PAA) e do Programa Nacional de Alimentação Escolar (PNAE) no fortalecimento da agricultura familiar e promoção da segurança alimentar. Temas de Administração Pública, v. 8, n. 2, 2013.

CAPELLESSO, A. J.; CAZELLA, A. A.; BÚRIGO, F. L. Evolução do Pronaf Crédito no Período 19962013: Redimensionando o acesso pelos cadastros de pessoa física. Revista de Economia e Sociologia Rural, v. 56, n. 3, p. 437-450, 2018.

CAPORAL, F.R.; PETERSEN, P. Agroecologia e políticas públicas na América Latina: o caso do Brasil. Agroecología, v. 6, p. 63-74, 2011.

CAZELLA, A.A.; CAPELLESSO, A.J.; MEDEIROS, M.; TECCHIO, A.; SENCÉBÉ, Y.; BÚRIGO, F.L. Políticas públicas de desenvolvimento rural no Brasil: o dilema entre inclusão produtiva e assistência social. Política e Sociedade, v. 15, p. 49-79, 2016.

CRAVO, M.S.; CORTELETTI, J.; NOGUEIRA, O.L.; SMYTH, T.J.; SOUZA, B.D.L. Sistema Bragantino: agricultura sustentável para a Amazônia. Documentos/Embrapa Amazônia Oriental. Belém, PA: Embrapa Amazônia Oriental, 101p. 2005. 
DAMASCENO, N.P.; KHAN, A.S.; LIMA, P.V. P.S. O impacto do Pronaf sobre a sustentabilidade da agricultura familiar, geração de emprego e renda no Estado do Ceará. Revista de Economia e Sociologia Rural, v. 49, n. 1, p. 129-156, 2011.

DIAS, M.M. As mudanças de direcionamento da Política Nacional de Assistência Técnica e Extensão Rural (PNATER) face ao difusionismo. Revista Oikos, Viçosa, v. 18, n. 2, p. 11-21, 2007. ELIAS, L.P.; BELIK, W.; CUNHA, M.P.; GUILHOTO, J.J.M. Impactos socioeconômicos do Programa Nacional de Alimentação Escolar na agricultura familiar de Santa Catarina. Revista de Economia e Sociologia Rural, v. 57, n. 2, p. 215-233, 2019.

ESQUERDO, V.F.S.; BERGAMASCO, S.M.P.P. Análise sobre o acesso aos programas de políticas públicas da agricultura familiar nos municípios do circuito das frutas (SP). Revista de Economia e Sociologia Rural, v. 52, p. 205-222, 2014.

FINATTO, R.A.; SALAMONI, G. Agricultura familiar e agroecologia: perfil da produção de base agroecológica do município de Pelotas/RS. Sociedade \& Natureza, v. 20, n. 2, p. 199-217, 2008.

FONTES, M.A.; RIBEIRO, G.T.; SIQUEIRA, E.R.; SIQUEIRA, P.Z.R.; RABANAL, J.E.M. Sistema agroflorestal sucessional como estilo produtivo para agricultura familiar em território de identidade rural, em Sergipe, Brasil. Revista Brasileira de Agroecologia, v. 8, n. 2, p. 112-120, 2013.

FREITAS, A.F.; FREITAS, A.F.; DIAS, M.M. Mudanças conceituais do desenvolvimento rural e suas influências nas políticas públicas. Revista de administração pública, v. 46, n. 6, p. 1575-1597, 2012.

FROBLICH, E.R.; FROBLICH, C.I.C. Metodologia de Pesquisa em estudos rurais: Investigando a partir de estudo de caso. In: CONTERATO, M.A.; RADOMSKY, G.F. W.; SCHNEIDER, S. Pesquisa em desenvolvimento rural: aportes teóricos e proposições metodológicas. Porto Alegre. Ed. UFRGS. V.1. 2014, p.57-76.

GIL, A.C. Estudo de caso: Fundamentação científica; subsídios para a coleta de dados; como redigir o relatório. São Paulo. Atlas, 2009.

GRISA, C.; SCHNEIDER, S. Três gerações de políticas públicas para a agricultura familiar e formas de interação entre sociedade e estado no Brasil. Revista de economia e sociologia rural, v. 52, p. 125-146, 2014.

HESPANHOL, R.A.M. Programa de Aquisição de Alimentos: limites e potencialidades de políticas de segurança alimentar para a agricultura familiar. Sociedade \& Natureza, v. 25, n. 3, p. 469-483, 2013.

HURTIENNE, T.P. Agricultura familiar e desenvolvimento rural sustentável na Amazônia. Novos cadernos NAEA, v. 8, n. 1, 2008.

INSTITUTO BRASILEIRO DE GEOGRAFIA E ESTATÍ́STICA. Censo Agropecuário 2017. Disponível em: https://cidades.ibge.gov.br/brasil/ap/macapa/pesquisa/24/76693. Acesso: 3 de fev., 2020.

KOHLHEPP, Gerd. Conflitos de interesse no ordenamento territorial da Amazônia brasileira. Estudos avançados, v. 16, n. 45, p. 37-61, 2002.

LANDINI, F.P. Problemas enfrentados por extensionistas rurais brasileiros e sua relação com suas concepções de extensão rural. Ciência Rural, v. 45, n. 2, p. 371-377, 2015.

LÉNA, P. Diversidade da fronteira agrícola na Amazônia. In: AUBERTIN, C.; BECKER, B. K. (Org.). Fronteiras. Brasília: Editora UnB, 1988. p. 61-90.

LIBERMANN, A.P.; BERTOLINI, G.R.F. Tendências de pesquisa em políticas públicas: uma avaliação do Programa Nacional de Alimentação Escolar-PNAE. Ciência e Saúde Coletiva, v. 20, p. 35333546, 2015.

LOMBA, R.M.; SILVA, I.C. O crédito rural na agricultura familiar no Estado do AmapáBrasil. Informe Gepec, v. 18, n. 2, p. 20-36, 2014.

MEDINA, G.; NOVAES, E. Percepção dos agricultores familiares brasileiros sobre suas condições de vida. Interações (Campo Grande), v. 15, n. 2, p. 385-397, 2014. 
NIEDERLE, P.A.; SCHIMITT, C.J.; SABOURIN, E.; PETERSEN, P.; ÁVILA, M.; ASSIS, W. A trajetória brasileira de construção de políticas públicas para a agroecologia. Redes, v. 24, n. 1, p. 270-291, 2019.

NODARI, R. O.; GUERRA, M. P. A agroecologia: estratégias de pesquisa e valores. Estudos avançados, v. 29, n. 83, p. 183-207, 2015.

OLIVEIRA, M.A.C.; SAMBUICHI, R.H.R.; SILVA, A.P.M. Experiências agroecológicas brasileiras: uma análise à luz do desenvolvimento local. Revista Brasileira de Agroecologia, v. 8, n. 2, p. 14-27, 2013.

PEREIRA, E.L.; NASCIMENTO, J.S. Efeitos do Pronaf sobre a produção agrícola familiar dos municípios tocantinenses. Revista de Economia e Sociologia Rural, v. 52, n. 1, p. 139-156, 2014. RODRIGUES, R.; SIQUEIRA, H.M.; BIANCARDI, C.C.S.; ANDRADE, M.A.N.; VALENTE, L.M.; PAULA, L.B. A aquisição de alimentos da agricultura familiar pelo PNAE no município de AlegreES. DEMETRA: Alimentação, Nutrição e Saúde, v. 12, n. 1, p. 91-112, 2017.

SÁ, T.D.A.; KATO, O.R. CARVALHO, C.J.R.; FIGUEREDO, R.O. Queimar ou não queimar?: De como produzir na Amazônia sem queimar. Revista USP, n. 72, p. 90-97, 2007.

SARON, F.A.; HESPANHOL, A.N. O Pronaf e as Políticas de Desenvolvimento Rural no Brasil: o desafio da (re) construção das políticas de apoio à agricultura familiar. Geo UERJ, v. 2, n. 23, p. 656-683, 2012.

SCHNEIDER, S.; MATTEI, L.; CAZELLA, A. Histórico, caracterização e dinâmica recente do PRONAF. In: SCHNEIDER, S.; SILVA, M.K.; MARQUES, P.E.M. Políticas Públicas e Participação Social no Brasil Rural. Porto Alegre: UFRGS, 2004. p. 21-50.

SILVA, I.C.; FILOCREÃO, A.S.M. Perspectivas para a agricultura familiar no Amapá In: Conflito, territorialidade e desenvolvimento: algumas reflexões sobre o campo amapaense. / Roni Mayer Lomba... [et. al.] Org.) - Dourados, MS: Ed. UFGD, p.83-112, 2014.

SILVA, L. M. Sistema Bragantino: Um método inovador e alternativo de cultivo e produção agrícola que engloba rotação e consórcio de culturas com técnicas de plantio direto. Revista Craibeiras de Agroecologia, v. 1, n. 1, 2018.

SIMÃO, G.L.; SILVA, E.A.; SILVEIRA, S.F.R. Grau de cobertura do Programa de Aquisição de Alimentos (PAA) junto aos agricultores familiares do estado de Minas Gerais. Revista de Economia e Sociologia Rural, v. 52, n. 3, p. 533-548, 2014.

VALENTE, A. S. O.; OLIVEIRA, E. C. P.; VIEIRA, T. A. Práticas agroecológicas em sistemas de uso da terra em uma comunidade rural na Amazônia Oriental, Brasil. Espacios (Caracas), v. 38, p. 1-9, 2017.

YIN, R.K. Estudo de Caso: Planejamento e Métodos. 4 Ed. Porto Alegre: Bookman, 2010.

ZANI, F.B.; COSTA, FREDERICO, L. Avaliação da implementação do Programa Nacional de Fortalecimento da Agricultura Familiar-novas perspectivas de análise. Revista de Administração Pública, v. 48, n. 4, p. 889-912, 2014. 